\title{
JOGOS EDUCATIVOS DIGITAIS E O ENSINO DO LUGAR EM FEIRA DE SANTANA: O LÚDICO NAS AULAS DE GEOGRAFIA
}

\author{
Daiane Correia de Vasconcelos ${ }^{1}$; Cléa Cardoso da Rocha ${ }^{2}$ \\ 1. Bolsista PIBIC/FAPESB, Graduando em Licenciatura em Geografia, Universidade Estadual de Feira de \\ Santana, e-mail: daianecvasconcelos@yahoo.com.br \\ 2. Orientadora, Departamento de Educação, Universidade Estadual de Feira de Santana, e-mail: \\ cleabase@yahoo.com.br
}

PALAVRAS-CHAVE: ensino de geografia; lugar; jogos educativos digitais.

\section{INTRODUÇÃO}

O processo de ensino-aprendizagem no contexto da sociedade contemporânea vem incorporando o uso das tecnologias da comunicação e informação para a construção do conhecimento. Assim, o uso de jogos educativos e didáticos digitais se adequa ao contexto atual, à necessidade da interação com as tecnologias atuais, e a uma proposta de abordagem interdisciplinar, rompendo assim as fronteiras da geografia escolar e perpassando outras áreas do conhecimento.

A Geografia é uma ciência responsável pela leitura espacial do mundo que, por sua vez, se desenvolve a partir da descrição, análise e explicação das relações entre sociedade e natureza. Portanto, pelo caráter interdisciplinar que apresenta, e buscando superar a epistemologia de cunho positivista, propõe-se que a geografia escolar seja trabalhada também nesta perspectiva no ensino básico, auxiliando na compreensão dos processos e dinâmicas que tangem à Feira de Santana enquanto lugar. Nesta perspectiva, Cavalcanti (2002) afirma que uma das contribuições do conhecimento geográfico é a consciência da espacialidade das coisas e dos fenômenos, vivenciados ou não como parte da história social, o que possibilita que os indivíduos se situem acerca dos lugares e dos acontecimentos que os rodeiam.

A partir de uma abordagem interdisciplinar, mediada pela geografia e educação ambiental, as escolas podem trabalhar em consonância com as políticas públicas para minimização de problemas socioambientais que afetam diversos lugares, em especial de Feira de Santana. Uma vez que a educação ambiental consiste "nos processos por meio dos quais o indivíduo e a coletividade constroem valores sociais, conhecimentos, habilidades, atitudes e competências voltadas para a conservação do meio ambiente, bem de uso comum do povo, essencial à sadia qualidade de vida e sua sustentabilidade" (BRASIL, 1999).

No entanto, observa-se que apenas a educação ambiental é insuficiente para este processo, uma vez que conhecer o seu lugar de vivência - aqui entendido como "(...) a base de reprodução da vida (...) o espaço passível de ser sentido, pensado, apropriado e vivido através do corpo" (CARLOS, 2007, p. 17-18) - se apresenta como um ponto de partida fundamental para preservá-lo, assim, percebe-se a relevância da educação geográfica neste contexto.

Segundo Andrade e Silva (2011), a educação geográfica pode possibilitar o desenvolvimento de competências e habilidades que permitam a formação de um cidadão que atue de forma autônoma e reflexiva, buscando amenizar os aspectos das crises socioambientais que acometem o contexto atual, através da leitura e compreensão de mundo e do reconhecimento do aluno como sujeito da construção do seu espaço de vivência, de modo que perceba que suas ações locais podem ter reflexos globais.

As informações aqui presentes referem-se às atividades desenvolvidas na pesquisa de Iniciação Científica "Jogos educativos digitais e o ensino do lugar em Feira de Santana: o lúdico nas aulas de geografia", abrangendo o período de 01 de agosto de 2015 a 31 de julho de 2016, cujo objetivo principal foi elaborar um jogo educativo 
digital para auxiliar na construção de conhecimentos sobre Feira de Santana, enquanto lugar, através de uma abordagem interdisciplinar aliando educação geográfica e ambiental.

O colégio investigado localiza-se na rua principal do segundo maior bairro de Feira de Santana e funciona a mais de 30 anos no local. É uma instituição pertencente à Rede Estadual de Ensino de Feira de Santana, que funciona durante todos os turnos, mantido por uma corporação e pela Secretaria de Educação e Cultura (SEC). Os alunos são, em grande parte, filhos de funcionários públicos residentes de vários bairros de Feira de Santana e, também, de cidades circunvizinhas.

Diante disso, foi proposto como questões norteadoras desta pesquisa: $O s$ professores das escolas campo utilizam jogos educativos e didáticos digitais no ensino da Geografia? De que forma é empregada a interdisciplinaridade nas aulas de Geografia? Como os jogos educativos e didáticos digitais, que empreguem uma abordagem interdisciplinar através da educação geográfica e educação ambiental, podem contribuir para o desenvolvimento da conscientização ambiental e a construção do conhecimento referente ao lugar? Na tentativa de responder aos questionamentos supracitados foi desenvolvida uma pesquisa de caráter qualitativo e extensionista, no âmbito da escola básica, objetivando elaborar jogos educativos e didáticos digitais, empregando uma abordagem interdisciplinar da educação ambiental com a educação geográfica, em parceria com professores das escolas campo para, posteriormente, desenvolver atividades de intervenção nas escolas com vistas a apresentar, experimentar e avaliar os mesmos.

\section{MATERIAL E MÉTODOS}

Para o desenvolvimento desta pesquisa foram empregados métodos que estão em consonância com o projeto "Lugar, Formação Docente e Elaboração de Material Didático sobre Feira de Santana/BA”, que é uma pesquisa qualitativa de caráter também extensionista. Dessa maneira, com a finalidade de atender aos objetivos propostos lançou-se mão de: 1- Levantamento bibliográfico sobre as temáticas abordadas; 2Discussão teórica com o grupo de pesquisa através dos encontros semanais no Grupo de Estudos do Projeto Lugar; 3- Identificação das temáticas/conteúdos para elaboração de jogos educativos e didáticos digitais, em parceria com os professores das escolas campo da pesquisa; 4- Elaboração de jogos educativos digitais e de propostas de atividades de intervenção para a apresentação, experimentação e avaliação no âmbito das escolas campo; 5- Desenvolvimento das atividades de intervenção para a socialização dos jogos educativos e didáticos digitais produzidos; 6- Aplicação de instrumentos de avaliação dos jogos digitais por parte dos discentes no que se refere ao seu uso, significância e utilidade na construção de conhecimentos referentes à Feira de Santana, enquanto lugar; 7- Sistematização e análise dos dados coletados através do acompanhamento do uso de jogos educativos e didáticos digitais; 8- Elaboração de relatórios.

\section{RESULTADOS E/OU DISCUSSÃO (ou Análise e discussão dos resultados)}

Durante o período da pesquisa de Iniciação Científica "Jogos educativos digitais e o ensino do lugar em Feira de Santana: o lúdico nas aulas de geografia" foi elaborado um labirinto digital intitulado "Pensando Verde no Espaço Urbano de Feira de Santana" com a finalidade de auxiliar na construção de conhecimentos sobre Feira de Santana, enquanto lugar, através de uma abordagem interdisciplinar aliando educação geográfica e ambiental.

Para a elaboração deste jogo, fez-se necessário aprender noções básicas de programação, visto que se pretendia, inicialmente, elaborar um jogo no Unity 3D por ser um ambiente de desenvolvimento integrado que possibilita a criação de softwares 
para diversas plataformas. Considerando a dificuldade de acesso à internet no âmbito escolar e a quantidade de computadores disponíveis, pretendia-se desenvolver um jogo voltado para uma plataforma que pudesse ser utilizada de modo off-line no computador ou até mesmo no celular.

Diante disso, foram realizadas aulas de programação com um estudante do Curso de Engenharia da Computação da UEFS, com a finalidade de aprender a linguagem de programação Python, que é considerada uma linguagem de alto nível em virtude da sua sintaxe bastante parecida com a escrita humana, distanciando-se, assim, da linguagem de máquina. A linguagem de programação Python é considerada mais simples em comparação com as demais, pois os códigos em Python são escritos de maneira mais direta dispensando caracteres que comumente são utilizados em outras linguagens. Outro fator de escolha desta linguagem para a criação do jogo foi por ser indicada para quem está iniciando no mundo da programação e, também, pela sua capacidade/versatilidade de desenvolver softwares para diversas plataformas (a partir do uso de ferramentas e frameworks que atendam as especificações de cada plataforma).

Para aprender a linguagem de programação Python, utilizou-se como suporte o site Code Academy, que contém 12 módulos de atividades online para aprender a linguagem, com uma sequência de exercícios obrigatórios necessários para o avanço dos módulos. Apesar dos tutoriais e suportes oferecidos pelo site Code Academy, bem como pelo instrutor, aprender uma linguagem de programação foi um grande desafio, pois, exige uma base fundamental e necessária de lógica matemática para entender como de fato esta linguagem funciona.

Além disso, ao longo dessas aulas algumas dificuldades foram encontradas, a exemplo dos graves problemas de conexão da internet disponibilizada pela UEFS, já que as aulas de programação aconteciam na instituição. Frente a esses problemas, fez-se necessário optar por outro ambiente de desenvolvimento integrado que não exigisse total conhecimento sobre linguagem de programação e, então, foi escolhido o Scratch, que é uma linguagem de programação com uma interface que possibilita a criação de softwares em browser, de modo online (no site do projeto Scratch) ou off-line (através da instalação em equipamento compatível).

Através do Scratch foi criado o labirinto "Pensando Verde no Espaço Urbano de Feira de Santana", este contempla situações cotidianas que representam atitudes que podem ser negativas ou positivas para a preservação do meio ambiente de Feira de Santana, com ênfase nos cursos d'água do município. Assim sendo, para jogar o labirinto é necessário proceder da seguinte forma: o jogador precisa chegar até o objeto "globo" (situado no final do labirinto) para vencê-lo, no entanto, ao longo do caminho o jogador encontra vários outros objetos que contém questões referentes às atitudes positivas e negativas, fazendo com que o jogador avance apenas se responder estas questões. Além disso, existem vários objetos representados por um ícone de "chave" que os levam para um outro cenário contemplando lagoas de Feira de Santana e informações a respeito delas.

Antes de levar o jogo para experimentação na escola ocorreu uma etapa diagnóstica com 29 alunos do $8^{\circ}$ ano, de uma escola-campo da pesquisa, da Rede Estadual de Ensino Feira de Santana, para coletar dados acerca do uso de jogos digitais nas aulas de geografia para o estudo do lugar, sobre a relação dos alunos com jogos digitais de maneira geral, e a expectativa dos mesmos em relação aos jogos digitais que contemplem conteúdos geográficos. Dentre os entrevistados, 26 gostam de jogos digitais, tendo como principal justificativa por ser algo que contribui para a distração e por ser uma forma de aprender ou, até mesmo, porque gostam de experimentar a criação dos criadores de jogos, como salientou um dos sujeitos. 
Todos afirmaram que seus professores nunca utilizaram jogos digitais na sala de aula e, ao serem questionados acerca da expectativa deles em relação ao uso deste recurso para o ensino dos conteúdos das disciplinas, afirmaram que facilitaria a aprendizagem e participação nas aulas e aumentaria o rendimento deles em sala de aula. Sobre jogos que abordem conteúdos geográficos, 22 afirmaram que seria uma maneira de aprender mais sobre a geografia e dinamizar as aulas, os demais sujeitos afirmaram que não gostariam deste tipo de jogo justificando suas repostas por não gostar de jogos digitais ou não gostar da disciplina.

Para socializar e avaliar o labirinto, houve a experienciação do labirinto com os mesmos sujeitos investigados anteriormente, durante três aulas de 50 minutos. Embora a partida do jogo seja pequena, o que possibilita ao jogador terminar a partida muito rápido, a experimentação ocorreu por três aulas porque os alunos não queriam parar de jogar, mesmo após finalizar o jogo. De modo geral, a maioria dos sujeitos investigados (24) fizeram uma avaliação positiva do jogo. Assim como da estrutura (21) e da temática do labirinto (25). Além disso, 26 sujeitos classificaram a linguagem como fácil ou muito fácil, e 23 sujeitos afirmaram que o labirinto contribuiu para a construção de novos conhecimentos, dentre eles: espaço urbano, coleta seletiva e lagoas de Feira de Santana. As principais sugestões feitas pelos sujeitos para futuras melhorias do jogo consistiram em: aumentar o nível de dificuldade das perguntas (dos aspectos positivos e negativos), elaborar outros níveis de labirinto, criação de outros imprevistos para o trajeto, labirintos com outras temáticas, lugares e gêneros de jogos, além de incluir mais de um jogador na mesma partida.

\section{CONSIDERAÇÕES FINAIS}

Com a sistematização e análise dos dados coletados através do questionário aplicado na escola campo de pesquisa, foi diagnosticado que os alunos percebem a importância do uso de jogos didáticos digitais para o processo de ensino-aprendizagem, embora seus professores nunca tenham utilizado este recurso em sala de aula. Os sujeitos investigados consideram os jogos digitais como uma possibilidade de recurso para facilitar a aprendizagem e dinamizar as aulas de geografia que até então é descrita como uma disciplina enfadonha, mnemônica e decorativa.

O labirinto "Pensando Verde no Espaço Urbano de Feira de Santana" foi considerado pelos alunos como um jogo de linguagem fácil que contribuiu para a construção de conhecimentos geográficos acerca de temáticas como espaço urbano, coletas seletivas, lagoas de Feira de Santana, bem como possibilitou a alguns alunos conhecer os lugares da cidade apresentados durante o trajeto do labirinto. Além disso, alguns sujeitos afirmaram que o uso de jogos digitais nas aulas de geografia poderia torná-las mais atrativas.

\section{REFERÊNCIAS}

ANDRADE, Lívia Iglesias de; SILVA, Augusto Cesar Pinheiro da. A educação geográfica como um caminho para a promoção de sustentabilidades: resgatando valores socioambientais com o $6^{\circ}$ ano do ensino fundamental. Dissertação (Mestrado) Pontifícia Universidade Católica do Rio de Janeiro, Departamento de Geografia, 2011.

BRASIL. Política Nacional de Educação Ambiental. Lei n ${ }^{\circ}$ 9.795, de 27 de abril de 1999. Disponível em: <http://www.planalto.gov.br/ccivil_03/leis/19795.htm>. Acesso em: 04 de abril de 2015.

CARLOS, Ana Fani Alessandri. O lugar no/do mundo. São Paulo: FFLCH, 2007.

CAVALCANTI, Lana de Souza. Geografia e Prática de Ensino. Goiânia: Alternativa, 2002. 